\title{
Cytoplasmic Staining of TTF-1 Antibody in the Diagnosis of Hepatocellular Carcinoma: Study on 299 Cases Using Tissue Microarray
}

\author{
Qinghua Cao, ${ }^{1}$ Fang Liu, ${ }^{1,2}$ Ping Xiao, ${ }^{1}$ Min Wang, ${ }^{1}$ Yuan Lin, ${ }^{1}$ Ziyin Ye, \\ Lihong Che, ${ }^{1}$ and Ling Xue ${ }^{1}$ \\ ${ }^{1}$ Department of Pathology, The First Affiliated Hospital, Sun Yat-sen University, Guangzhou, Guangdong 510080, China \\ ${ }^{2}$ Cancer Center, Nanfang Hospital of Southern Medical University, Guangzhou, Guangdong 51055, China
}

Correspondence should be addressed to Ling Xue, xuel@mail.sysu.edu.cn

Received 14 April 2011; Accepted 9 May 2011

Academic Editor: V. J. Amatya

Copyright ( 2011 Qinghua Cao et al. This is an open access article distributed under the Creative Commons Attribution License, which permits unrestricted use, distribution, and reproduction in any medium, provided the original work is properly cited.

The diagnosis of hepatocellular carcinoma (HCC) remains obscure in some complicated cases. Thyroid transcription factor-1 (TTF-1) was presumed to be helpful in the diagnosis of HCC. This paper aims to study the utility of TTF-1 in the diagnosis and differential diagnosis of HCC and to assign clinicopathological correlations. Immunohistochemical detection of TTF-1 is performed with tissue microarray which contains a total of 781 cases including 299 hepatocellular carcinomas (HCCs), 31 intrahepaticcholangiocarcinomas (ICCs), 86 metastatic adenocarcinomas (MACs), 5 metastatic hepatocellular carcinomas (mHCCs), 9 hepatoblastomas (HBs), 40 renal clear cell carcinomas (RCCs), 215 adjacent nonneoplastic hepatic tissue, and 96 normal hepatic tissue. The result shows that TTF-1 is positive in 55.2\% (165/299) HCCs, 6.4\% (2/31) ICCs, 3.5\% (3/86) MACs, 60\% (3/5) mHCCs, 33.3\% (3/9) HBs, 0\% (0/40) RCCs, 99.0\% (213/215) adjacent nonneoplastic hepatic tissue, and 95.8\% (93/96) normal hepatic tissue. Expression of TTF-1 is correlated with differentiation of HCC, but not with patients' age, gender, serum AFP, tumor size, number of tumor nodules, and tumor thrombus in vein or bile duct. These data suggest that TTF-1 antibody is sensitive and specific in HCC and might serve as a candidate for the diagnosis and differential diagnosis of HCC.

\section{Introduction}

Hepatocellular carcinoma (HCC) is the most common malignancies in liver. Generally accurate pathological diagnoses are not difficult to be reached. However, confirmatory methods are still required in certain complicated cases. Although some immunohistochemical markers, such as $\alpha$ fetoprotein (AFP), hepatocyte paraffin 1 (Hep Par1), and CK8, have played critical parts in practice, each of them has showed some limitations [1,2]. Exploring for more valuable immunohistochemical markers is of great help to establish the diagnosis of HCC in those uncertain cases. Thyroid transcription factor-1 (TTF-1) has been commonly used in the diagnosis of thyroid and pulmonary tumors, prediction for prognosis of which has been proved in the literature [3$5]$. In the past years, TTF- 1 staining was well known to be nuclear, with only occasional reports of cytoplasmic staining. However, increasing attention has been drawn to the significance of cytoplasmic staining of TTF-1 in both HCC and nonneoplastic hepatic tissue recently $[1,6,7]$, which suggested that TTF-1 may serve as the potential valuable marker to confirm the diagnosis of HCC in uncertain cases. Nevertheless, in previous studies, there are not enough number of cases to verify the significance of cytoplasmic staining of TTF- 1 nor did they correlate the expression of TTF- 1 with clinical data. These limited their power of persuasion. In the present study, immunohistochemical detection of TTF-1 is performed with tissue microarray containing 776 specimens, and the clinicopathological correlations were analyzed to verify the diagnostic significance of TTF-1 in HCC.

\section{Materials and Methods}

2.1. Case Selection. A total of 781 specimens included 299 primary hepatocellular carcinomas (HCCs), 31 intrahepaticcholangiocarcinomas (ICCs), 86 metastatic adenocarcinomas (MACs) (50 are hepatic metastases from colorectal 
TABLE 1: Clinical and pathologic information.

\begin{tabular}{|c|c|}
\hline Factor & Cases load \\
\hline \multicolumn{2}{|l|}{ Age } \\
\hline$\leq 35 y$ & $40(13.4 \%)$ \\
\hline$>35 y$ & $259(86.6 \%)$ \\
\hline \multicolumn{2}{|l|}{ Sex } \\
\hline Male & $276(92.3 \%)$ \\
\hline Female & $23(7.7 \%)$ \\
\hline \multicolumn{2}{|l|}{ Serum AFP } \\
\hline$\leq 400 \mathrm{ug} / \mathrm{L}$ & $157(52.5 \%)$ \\
\hline$>400 \mathrm{ug} / \mathrm{L}$ & $142(47.5 \%)$ \\
\hline \multicolumn{2}{|l|}{ Tumor size } \\
\hline Single and $<3 \mathrm{~cm}$ & $16(5.7 \%)$ \\
\hline$\geq 3 \mathrm{~cm}$ & $283(94.6 \%)$ \\
\hline \multicolumn{2}{|l|}{ No. of nodules } \\
\hline 1 & $178(59.5 \%)$ \\
\hline$\geq 2$ & $121(40.5 \%)$ \\
\hline \multicolumn{2}{|c|}{ Vein or bile duct tumor thrombus } \\
\hline Present & $93(31.1 \%)$ \\
\hline Absent & $206(68.9 \%)$ \\
\hline \multicolumn{2}{|c|}{ Edmondson-Sterner grade } \\
\hline $\mathrm{I}+\mathrm{II}$ & $234(78.3 \%)$ \\
\hline III + IV & $65(21.7 \%)$ \\
\hline \multicolumn{2}{|l|}{ Histological pattern } \\
\hline Trabecular & $274(91.6 \%)$ \\
\hline Pseudoglandular & $17(5.7 \%)$ \\
\hline Solid & $8(2.7 \%)$ \\
\hline
\end{tabular}

carcinomas, 36 are from stomach), 5 metastatic HCCs (mHCCs) (4 were vertebra metastasis, 1 was lymph node metastasis), 9 hepatoblastomas (HBs), 40 renal clear cell carcinomas (RCCs), 215 adjacent non-neoplastic hepatic tissue (hepatic tissue adjacent to HCC), and 96 normal hepatic tissue (hepatic tissue adjacent to hemangioma). 299 HCC cases were classified as well differentiated (grade I+ II, 234 cases) and poorly differentiated (grade III + IV, 65 cases) according to Edmondson-Sterner grade criteria [8]. All cases were retrieved from the archivements of the first affiliated hospital, Sun Yat-sen University from January 2006 to july 2008, and these cases were selected and reviewed by the authors. Selection was based on the availability of the paraffin blocks and whether there was adequate tissue in the paraffin blocks for the tissue microarray study. All patients were of Chinese origin. None of the patients had received any therapy before surgical operation, including chemoembolization or chemotherapy.

2.2. Construction of Tissue Microarrays. The tissue microarray block was constructed using a tissue microarray (Beecher
TABLE 2: TTF-1 expression in HCC.

\begin{tabular}{lcc}
\hline & Score & No. (\% of all cases) \\
\hline \multirow{2}{*}{ Negative } & 0 & $124(41.4 \%)$ \\
& 1 & $10(3.3 \%)$ \\
Moderate positive & 2 & $23(7.7 \%)$ \\
& 3 & $10(3.3 \%)$ \\
Strong positive & 4 & $21(7 \%)$ \\
& 6 & $111(37.1 \%)$ \\
\hline
\end{tabular}

TABLE 3: TTF-1 expression in tissue microarray.

\begin{tabular}{lc}
\hline Case group & $\%$ of positive staining \\
\hline HCC & $55.2 \%(165 / 299)$ \\
ICC & $6.4 \%(2 / 31)$ \\
MAC & $3.5 \%(3 / 86)$ \\
mHCC & $60 \%(3 / 5)$ \\
RCC & $0 \%(0 / 40)$ \\
HB & $33.3 \%(3 / 9)$ \\
Adjacent non-neoplastic hepatic tissue & $99.0 \%(213 / 215)$ \\
Normal hepatic tissue & $95.8 \%(93 / 96)$ \\
\hline
\end{tabular}

TABLE 4: TTF-1 expression in different histopathological patterns of HCC.

\begin{tabular}{lcc}
\hline $\begin{array}{l}\text { Histopathological } \\
\text { pattern }\end{array}$ & $\begin{array}{c}\text { No. reactive } \\
\text { (No. evaluated) }\end{array}$ & $\begin{array}{c}\text { \% of } \\
\text { expression }\end{array}$ \\
\hline Trabecular & $154(274)$ & $56.2 \%$ \\
Pseudoglandular & $9(17)$ & $52.9 \%$ \\
Solid & $2(8)$ & $25.0 \%$ \\
\hline
\end{tabular}

Instruments, Silver Spring, MD) as described previously. The tissue samples consist of $299 \mathrm{HCCs}, 31 \mathrm{CCs}$, $86 \mathrm{MACs}$, 40 RCCs, 215 adjacent non-tumor livers (liver tissue surrounding HCC), and 96 normal livers. Two cores were punched in each case; each of tissue cores is $1.0 \mathrm{~mm}$ in diameter; consecutive $4 \mu \mathrm{m}$ thick sections were cut and airdried overnight. One section from the tissue microarray block was stained with hematoxylin and eosin to confirm the homogeneity of the cell populations in the tissue samples. $4 \mathrm{mHCCs}$ and $9 \mathrm{HBs}$ were performed as conventional sections.

2.3. Immunohistochemistry. The sections were deparaffinized in xylene and rehydrated in graded series of ethanol. For antigen retrieval, the sections were immersed in EDTA solution ( $\mathrm{pH} 9.0)$ and processed in a heated steamer at $100^{\circ} \mathrm{C}$ for 5 minutes. After cooling at room temperature for 30 minutes, slides were washed in phosphate-buffered saline solution ( $\mathrm{pH} 7.4$ ) and treated with $3 \%$ hydrogen peroxide for 15 minutes. The sections were incubated for 
TABLE 5: Clinicopathologic correlations between biologic factors and patients with HCC.

\begin{tabular}{|c|c|c|c|}
\hline Factor & No. reactive (No. evaluated) & Rate of expression & $P$ values \\
\hline \multicolumn{4}{|l|}{ Sex } \\
\hline Female & $13(23)$ & $56.5 \%$ & \\
\hline Male & $152(276)$ & $55.1 \%$ & $P=0.89$ \\
\hline \multicolumn{4}{|l|}{ Age } \\
\hline$\leq 35 \mathrm{y}$ & $22(40)$ & $55.0 \%$ & \\
\hline$>35 \mathrm{y}$ & $143(259)$ & $55.2 \%$ & $P=0.56$ \\
\hline \multicolumn{4}{|l|}{ Serum AFP } \\
\hline$\leq 400 \mathrm{ug} / \mathrm{l}$ & $81(157)$ & $51.9 \%$ & \\
\hline$>400 \mathrm{ug} / \mathrm{l}$ & $84(142)$ & $59.1 \%$ & $P=0.12$ \\
\hline \multicolumn{4}{|l|}{ Tumor size } \\
\hline Single and $<3 \mathrm{~cm}$ & $11(16)$ & $68.7 \%$ & \\
\hline$\geq 3 \mathrm{~cm}$ & $154(283)$ & $54.4 \%$ & $P=0.19$ \\
\hline \multicolumn{4}{|l|}{ No. of nodules } \\
\hline 1 & $98(178)$ & $53.9 \%$ & \\
\hline$\geq 2$ & $67(121)$ & $53.7 \%$ & $P=0.53$ \\
\hline \multicolumn{4}{|c|}{ Vein or bile duct tumor thrombus } \\
\hline Present & $54(93)$ & $58.0 \%$ & \\
\hline Absent & $111(206)$ & $53.8 \%$ & $P=0.45$ \\
\hline \multicolumn{4}{|c|}{ Edmondson-Sterner grade } \\
\hline $\mathrm{I}+\mathrm{II}$ & $151(234)$ & $64.5 \%$ & \\
\hline $\mathrm{III}+\mathrm{IV}$ & $14(65)$ & $21.5 \%$ & $P=0.01^{*}$ \\
\hline
\end{tabular}

1 hour with the monoclonal mouse antibody specific for TTF-1 (clone 8G7G3/1, Santa Cruz, USA) at a dilution of $1: 100$, then washed with PBS solution ( $\mathrm{pH} 7.4)$, and incubated for 30 minutes at $37^{\circ} \mathrm{C}$ with the secondary antibody (catalog: PV-8000, Zhongshan Co., itd, China), which is a biotin-free detection system that consists of a secondary antibody covalently linked to peroxidase-coated dextrose polymers. Finally, the sections were visualized with 3,3'diaminobenzidine (DAB, DAKO) and counterstained with hematoxylin. Normal thyroid tissue sections were used as positive controls. Negative controls substituted PBS buffer for primary antibody.

2.4. Interpretation and Scoring of Immunohistochemical Preparations. Nuclear and/or cytoplasmic expression of TTF-1 was considered positive immunostaining. Expression within tumor stroma was not specifically recorded. For all, both extent (on the basis of the percentage of positive cells) and intensity of immunostaining were evaluated by a semiquantitative system. Extent was scored as follows: 0, $\leq 5 \% ; 1+$ ( 1 point), $6 \%$ to $25 \% ; 2+$ ( 2 points), $26 \%$ to $50 \% ; 3+$ (3 points), $>51 \%$. Intensity was arbitrarily scored as weak ( 0 point), moderate ( 1 point), or strong ( 2 points).
Intensity was designated as weak when immunostaining was present but only barely detectable. To correlate extent and intensity of immunostaining, these values in positive cases were converted into composite immunohistochemical scores by multiplying the individual scores of extent by intensity (possible range of values from 0 to 6). For example, a moderate $3+$ extent ( 3 points) and moderate intensity of immunostaining ( 2 points) would have an immunohistochemical composite score of $3 \times 2=6$ [9]; according to this, the results of immunostaining were classified as negative $(0$, $1)$, moderate positive $(2,3)$, and strong positive $(4,6)$.

2.5. Statistical Analysis. Chi-square analysis was used for statistical analysis. A $P$ value of less than .05 was considered statistically significant. For all statistics, SPSS 13.0 for Windows software (or other) was used.

\section{Results}

3.1. Clinicopathological Finding in Hepatocellular Carcinoma. The clinicopathological features of the 299 patients with HCC in the study group are summarized in Table 1. Patients' age ranged from 9 month to 75 years (median age $50 \mathrm{yr}$, 


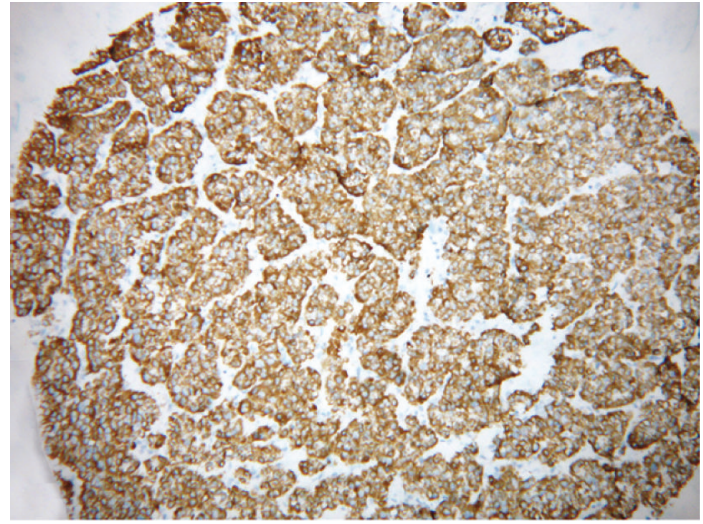

(a)

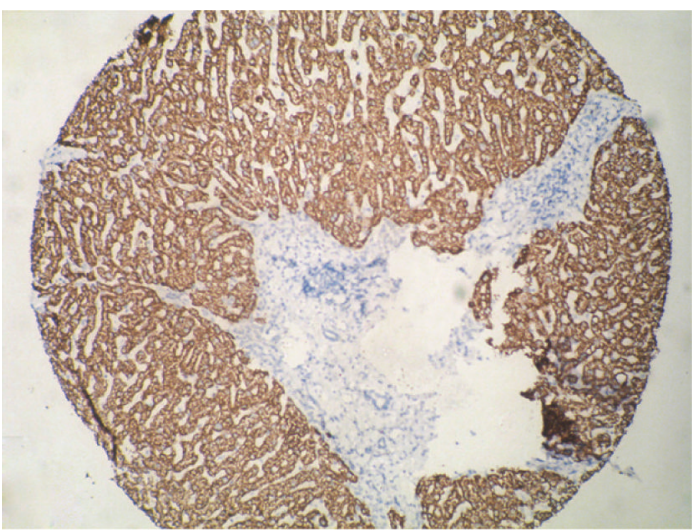

(c)

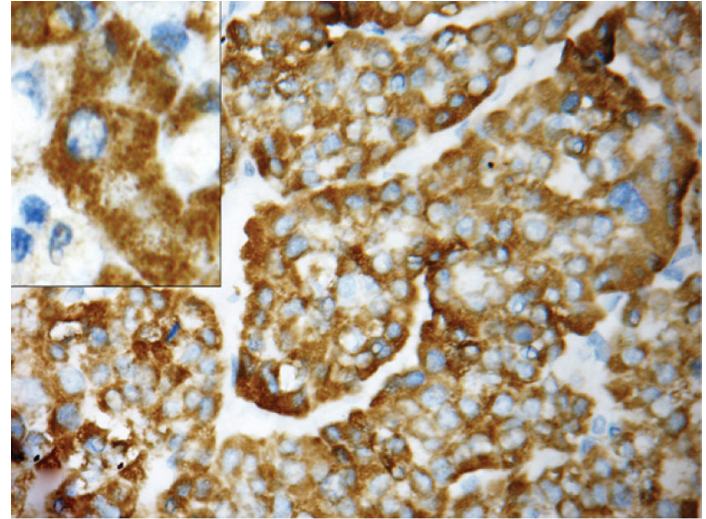

(b)

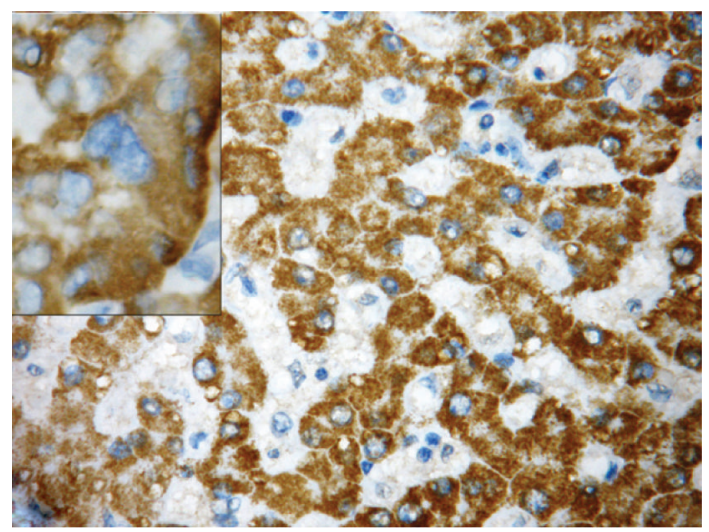

(d)

FIgURE 1: (a) (b) TTF-1 expressed in HCC, inset: high magnification of the cytoplasmic staining; (c) (d) TTF-1 staining in adjacent nonneoplastic hepatic tissue. Bile duct epitheliums, endothelial cells, were negative for TTF-1. Inset: high magnification of the cytoplasm staining $($ a, c: IHC $\times 40 ;$ b, d: IHC $\times 200)$.

mean age $49 \mathrm{yr})$. The patients consisted of 23 females and 276 males with a ratio of $1: 12$. Serum AFP concentration over $400 \mathrm{ng} / \mathrm{mL}$ was seen in $47.5 \%$ of patients; tumor size was large in most cases (diameter range 1 to $29 \mathrm{~cm}$, median $7.1 \mathrm{~cm}$; mean $8.1 \mathrm{~cm}$ ). Tumor thrombi in veins or bile ducts were found in 93 patients (31.1\%; 93/299). 299 cases of HCC were graded according to the Edmondson-Steiner grade criteria: $234(78.3 \%)$ cases were well differentiated (grade I+ II), and $65(21.7 \%)$ were poorly differentiated (grade III + IV). The histological type of HCC included trabecular type $(91.6 \%, 274 / 299)$, pseudoglandular type (5.7\%, 17/299), and solid type $(2.7 \%, 8 / 299)$ [10].

3.2. TTF-1 Expression. TTF-1 was positive in 165 (55.2\%) of 299 HCCs, within which 132 of $165(80 \%)$ were scored as strong positivity (Table 2). All of these positive cases showed cytoplasmic staining for TTF-1 with diffuse and brown-yellow granular patterns (Figures 1(a) and 1(b)); no nuclear staining was noted. $213(99.0 \%)$ of 215 adjacent non-neoplastic hepatic tissue and $93(95.8 \%)$ of 96 normal hepatic tissue were positive for TTF-1 antibody. In both adjacent non-neoplastic hepatic tissue and normal hepatic tissue, strong cytoplasmic positivity was unexceptionally detected. While TTF-1 was negative in bile duct epitheliums, endothelial cells and Kupffer cells (Figures 1(c) and 1(d)). In MACs, 3 (3.5\%) of 86 cases showing cytoplasm staining with diffuse and weak reactivity, all of these were welldifferentiated adenocarcinoma. In ICCs, 2 (6.4\%) of 31 caes, showed weak cytoplasmic staining for TTF-1. No one RCC was positive for TTF-1. 3 mHCCs $(60 \%)$ revealed cytoplasmic staining for TTF-1 (all of them were vertebra metastasis) (Figures 2(g) and 2(h)). Additionally, in 9 HBs, 3 cases demonstrated cytoplasmic staining for TTF-1 (the staining type was similar to HCC), with only fetal cells showed positive, while embryonal cells-relatively immature-did not react with TTF-1 (Figures 2(e) and 2(f)). Positive control (thyroid tissue) presented clear and strong nuclear staining. Negative control does not react. The differences between HCC and all of ICC, RCC, MAC, and HB were statistically significant (Table 3). As for different histopathological patterns of HCC, cytoplasmic staining was presented in 56.2\% of trabecular pattern (154/274), including 2 cases of clear 


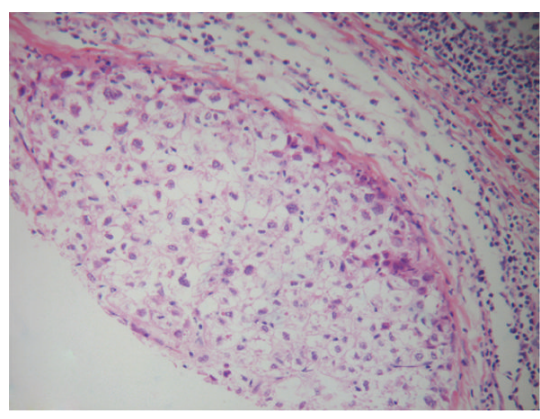

(a)

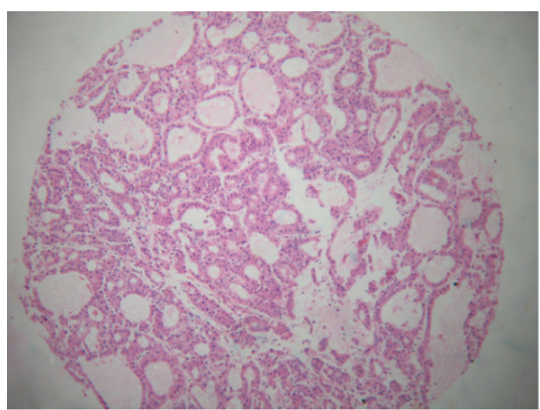

(c)

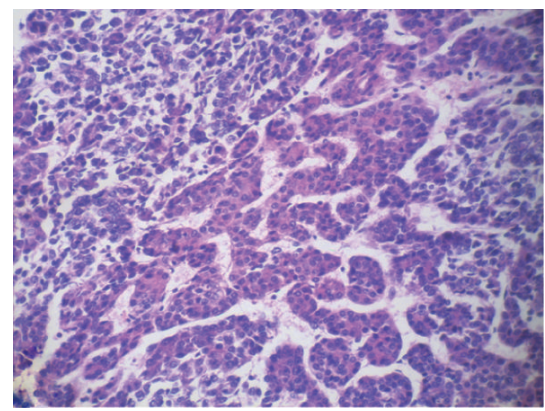

(e)

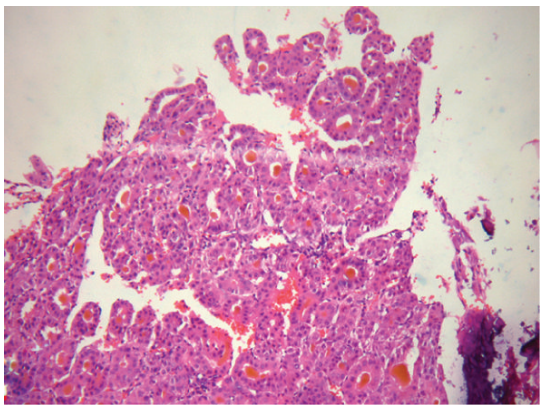

(g)

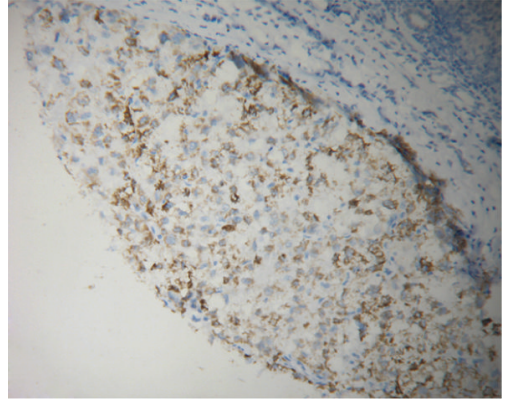

(b)

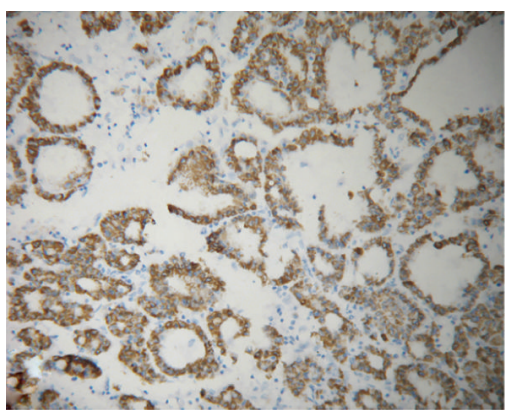

(d)

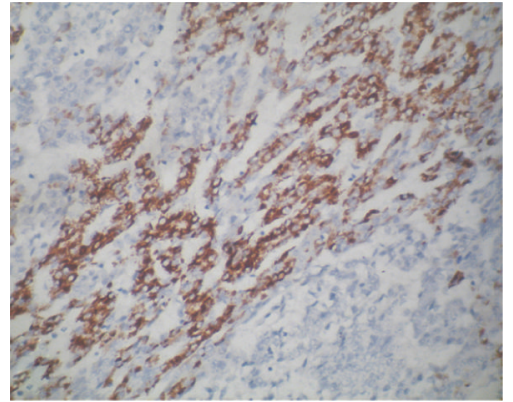

(f)

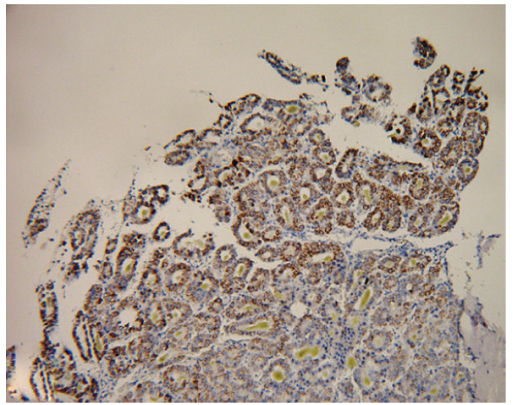

(h)

FIGURE 2: (a) HCC with clear cell $(\mathrm{HE} \times 100)$; (b) clear cell HCC immunoreactive for TTF-1 (IHC $\times 100)$; (c) pseudoglandular type HCC $(\mathrm{HE} \times 40)$; (d) pseudoglandular type HCC immunoreactive for TTF-1 (IHC $\times 100)$; (e) hepatoblastoma $(\mathrm{HE} \times 100)$; (f) TTF-1 expressed in HB. Fetal cells were positive for TTF-1 (IHC $\times 100)$; $(\mathrm{g})$ vertebra metastasis of HCC $(\mathrm{HE} \times 100)$; (h) vertebra metastasis of HCC react with TTF-1 $($ IHC $\times 100)$. 
cell type $(22.2 \%, 2 / 9)$ (Figures $2(\mathrm{a})$ and $2(\mathrm{~b})), 52.9 \%$ of pseudoglandular pattern (9/17) (Figures 2(c) and 2(d)), and $25 \%$ of solid patterns (2/8) (Table 4$)$.

3.3. Clinicopathological Correlations. Expression of TTF1 correlated significantly with the grade of HCC, which was stronger in well-differentiated carcinoma (grade I + II) $(64.5 \% ; 151 / 234)$ than in poorly differentiated ones (grade III + IV) $(21.5 \% ; 14 / 65)$. The difference between high-grade and low-grade carcinoma was significant $(P=.01)$. There was no correlation between TTF-1 expression and sex, age, serum AFP, tumor size, number of nodules, and vein or bile duct tumor thrombus (Table 5).

\section{Discussion}

TTF-1 is a $38-\mathrm{kDa}$ nuclear protein initially identified as a mediator of thyroid-specific gene transcription, the code gene located on chromosome $14 \mathrm{q} 13$. It is a member of the NKx2 family of homeodomain transcription factors and is expressed in thyroid and lung tissues [11].

Expression of TTF-1 was characteristically seen in the nuclei of tumor cells origin from thyroid and lung. Cytoplasmic staining was reported occasionally and presumed as a nonspecific staining pattern previously $[12,13]$. However, the diagnostic utility of cytoplasmic reactivity of TTF-1 has drawn the interest of some researchers recently. Rates of cytoplasmic reactivity of TTF-1 ranged from $64 \%$ up to $93 \%$ in HCC in the literature $[1,6,7]$, which was totally different from those found in lung and thyroid tumors, suggesting the potential application of TTF-1 antibody in the diagnosis of HCC. Nevertheless, there was not a consensus of opinion in terms of the mechanism of cytoplasmic staining of TTF-1, based on the similar staining type between TTF-1 and HPA; Pang et al. [14] draw conclusion that different epitopes to HPA and TTF-1 share the same protein molecule in hepatocyte mitochondria using immunoelectron microscopic. While a recent study by $\mathrm{Gu}$ et al. [15] demonstrates that TTF-1 immunoreactivity in the hepatocyte cytoplasm is due to an approximately $160-\mathrm{kd}$ protein and this unique protein is neither an alternative splicing product of TTF-1 nor does it express in thyroid and lung tissues in light of RNA and protein analyses; in our study cytoplasmic TTF-1 staining in HCC and normal hepatocytes is a reliable reaction, as endogenous peroxides were excluded by using 3\% hydrogen peroxide in the process, and artifact from endogenous biotin in hepatocytes could be eliminated in the biotin-free detection system. In addition, external positive and negative controls, as well as internal negative control such as bile duct epithelium, endothelial cells, and Kupffer cells, were used to verify the specificity of the antibody. Although similar results have been described before in the literature, the case numbers were not large enough to convince the specificity of cytoplasmic TTF-1 staining in hepatocytes. Our study includes $299 \mathrm{HCCs}$ using tissue microarray to detect the expression of TTF-1 and finds that the positive staining type of TTF-1 in HCC, hepatic tissue, and adjacent nonneoplastic hepatic tissue is exclusively cytoplasmic reactivity, without any nuclear staining case detected. Our study shows that 55.2\% (165/299) HCCs are positive for TTF-1, which are significantly higher than that in ICC (6.4\%), MAC (3.5\%), and RCC (0\%). In addition to this, 60\% (3/5) metastatic HCCs showed positive reactivity. And the expression rate of TTF-1 in adjacent non-neoplastic hepatic tissue and normal hepatic tissue is up to $99.0 \%$ and $95.8 \%$, respectively. These results proved that cytoplasmic staining of TTF-1 is specific to HCC and hepatocytes. It can be used as a candidate marker in the diagnosis and differential diagnosis of HCC. Even the application of detecting the original tissue of metastatic carcinoma would be possible. The staining type, cytoplasmic or nuclear, could do favor to distinguish the original tissue.

Nevertheless, the expression rate of TTF-1 in HCC in our study (55.2\%) was lower compared with previous studies which may attribute to difference in number of cases in the studies, and different antibody agent applied as well. Furthermore, we investigated the correlations between the expression of TTF-1 in HCC and their clinicopathological features, which show that tumor grades are parallel with the level of TTF-1, with the expression rates being lower in highgrade cases (poorly differentiated) compared with low-grade cases (well differentiated), $21.5 \%$ versus $64.5 \%$, respectively. However, there is no correlation between TTF-1 expression and sex, age, level of serum AFP, tumor size, number of nodules, and vein or bile duct tumor thrombus. In addition to this, an interesting phenomenon is found in HB. TTF-1 only expresses in fetal cells, but not embryonal cells, which are less differentiated in morphology than fetal cells in HBs [16]. It seems that expression rate of TTF-1 in HCC and HB (neoplastic component) correlates with differentiation stage of tumor. However, profound senses of these findings are needed to be explored in the future.

In summary, our study focuses on the utility of TTF-1 in the diagnosis and differential diagnosis of HCC with a large number of cases using tissue microarray. Cytoplasmic TTF-1 staining is sensitive and specific to HCC. The clinicopathological correlations are analyzed in our study, which may help to understand what role cytoplasmic staining of TTF-1 plays in HCC exactly. In all, TTF-1 antibody may serve as a candidate for making diagnosis and differential diagnosis of HCC.

\section{References}

[1] M. Gokden and A. Shinde, "Recent immunohistochemical markers in the differential diagnosis of primary and metastatic carcinomas of the liver," Diagnostic Cytopathology, vol. 33, no. 3, pp. 166-172, 2005.

[2] V. Varma and C. Cohen, "Immunohistochemical and molecular markers in the diagnosis of hepatocellular carcinoma," Advances in anatomic pathology, vol. 11, no. 5, pp. 239-249, 2004.

[3] S. N. Agoff, L. W. Lamps, A. T. Philip et al., "Thyroid transcription factor-1 is expressed in extrapulmonary small cell carcinomas but not in other extrapulmonary neuroendocrine tumors," Modern Pathology, vol. 13, no. 3, pp. 238-242, 2000.

[4] N. G. Ordóñez, "Value of thyroid transcription factor-1 immunostaining in distinguishing small cell lung carcinomas from other small cell carcinomas," American Journal of Surgical Pathology, vol. 24, no. 9, pp. 1217-1223, 2000. 
[5] A. L. Folpe, M. D. Gown, L. W. Lamps et al., "Thyroid transcription factor-1: immunohistochemical evaluation in pulmonary neuroendocrine tumors," Modern Pathology, vol. 12, no. 1, pp. 5-8, 1999.

[6] T. J. Wieczorek, J. L. Pinkus, J. N. Glickman, and G. S. Pinkus, "Comparison of thyroid transcription factor-1 and hepatocyte antigen immunohistochemical analysis in the differential diagnosis of hepatocellular carcinoma, metastatic adenocarcinoma, renal cell carcinoma, and adrenal cortical carcinoma," American Journal of Clinical Pathology, vol. 118, no. 6, pp. 911-921, 2002.

[7] J.-Y. Lei, P. A. Bourne, P. A. DiSant' Agnese, and J. Huang, "Cytoplasmic staining of TTF-1 in the differential diagnosis of hepatocellular carcinoma vs cholangiocarcinoma and metastatic carcinoma of the liver," American Journal of Clinical Pathology, vol. 125, no. 4, pp. 519-525, 2006.

[8] H. Edmondson, "Primary carcinoma of the liver: a study of 100 cases among 48,900 necropsies," Cancer, vol. 7, pp. 462$503,1954$.

[9] C. Zhao, G. L. Bratthauer, R. Barner, and R. Vang, "Diagnostic utility of WT1 immunostaining in ovarian Sertoli cell tumor," American Journal of Surgical Pathology, vol. 31, no. 9, pp. 13781386, 2007.

[10] S. Hirohashi, K. G. Ishak, M. Kojiro et al., "Hepatocellular carcinoma," in Pathology and Genetics of Tumours of the Digestive System, S. R. Hamilton and L. A. Aaltonen, Eds., IARC Press, Lyon, France, 2000.

[11] E. Compérat, F. Zhang, C. Perrotin et al., "Variable sensitivity and specificity of TTF-1 antibodies in lung metastatic adenocarcinoma of colorectal origin," Modern Pathology, vol. 18, no. 10, pp. 1371-1376, 2005.

[12] J. L. Hecht, J. L. Pinkus, L. J. Weinstein, and G. S. Pinkus, "The value of thyroid transcription factor-1 in cytologic preparations as a marker for metastatic adenocarcinoma of lung origin," American Journal of Clinical Pathology, vol. 116, no. 4, pp. 483-488, 2001.

[13] P. A. Bejarano, Y. E. Nikiforov, E. S. Swenson, and P. W. Biddinger, "Thyroid transcription factor-1, thyroglobulin, cytokeratin 7, and cytokeratin 20 in thyroid neoplasms," Applied Immunohistochemistry and Molecular Morphology, vol. 8, no. 3, pp. 189-194, 2000.

[14] Y. Pang, M. Von Turkovich, H. Wu et al., "The binding of thyroid transcription factor-1 and hepatocyte paraffin 1 to mitochondrial proteins in hepatocytes: a molecular and immunoelectron microscopic study," American Journal of Clinical Pathology, vol. 125, no. 5, pp. 722-726, 2006.

[15] K. Gu, V. Shah, C. Ma, L. Zhang, and M. Yang, "Cytoplasmic immunoreactivity of thyroid transcription factor-1 (Clone 8G7G3/1) in hepatocytes: true positivity or cross-reaction?" American Journal of Clinical Pathology, vol. 128, no. 3, pp. 382388, 2007.

[16] M. M. Cajaiba, J. I. Neves, F. F. Casarotti et al., "Hepatoblastomas and liver development: a study of cytokeratin immunoexpression in twenty-nine hepatoblastomas," Pediatric and Developmental Pathology, vol. 9, no. 3, pp. 196-202, 2006. 


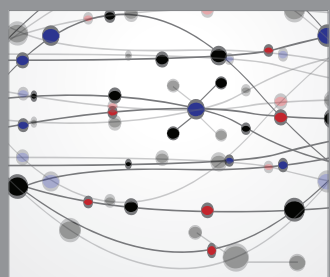

The Scientific World Journal
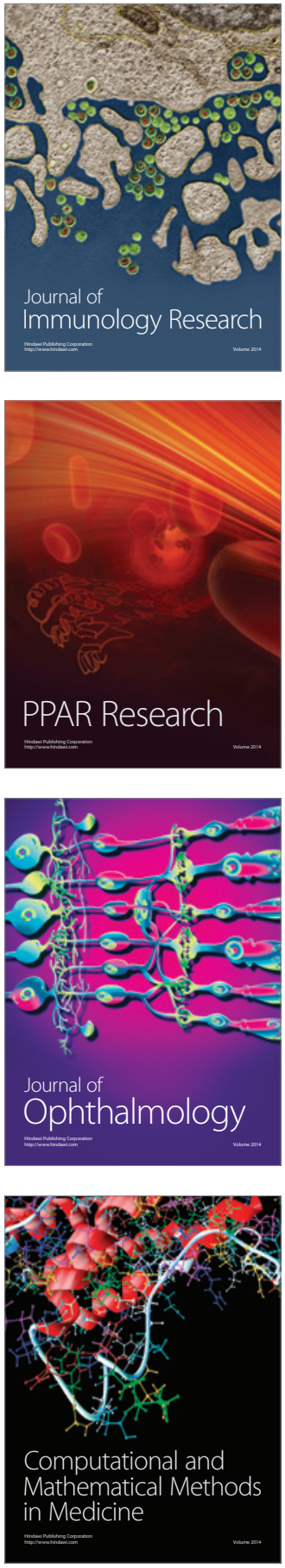

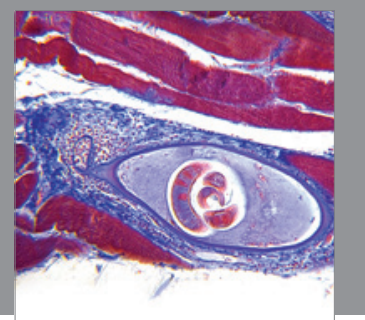

Gastroenterology

Research and Practice
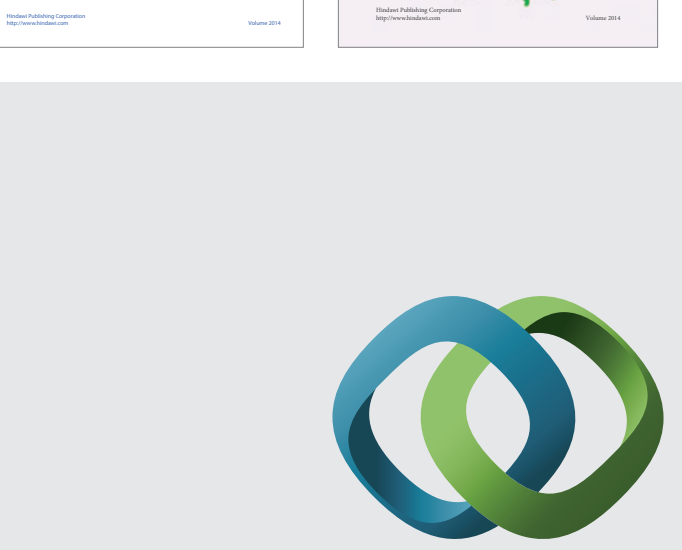

\section{Hindawi}

Submit your manuscripts at

http://www.hindawi.com
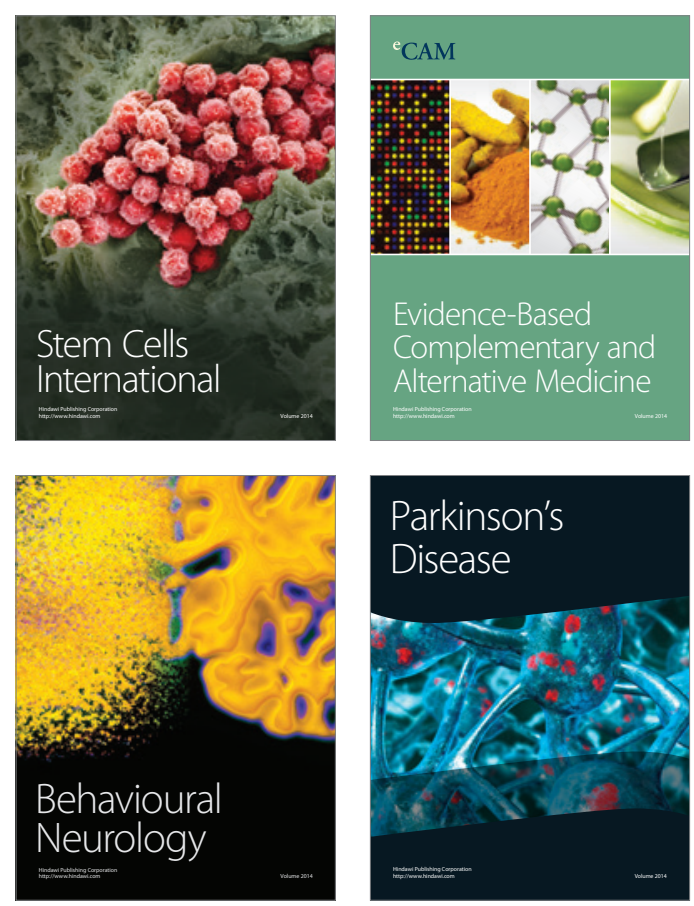

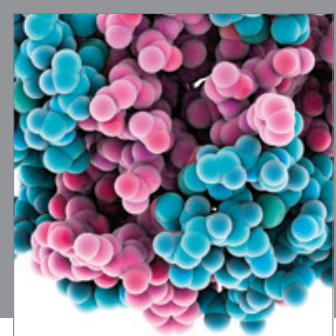

Journal of
Diabetes Research

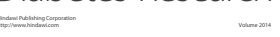

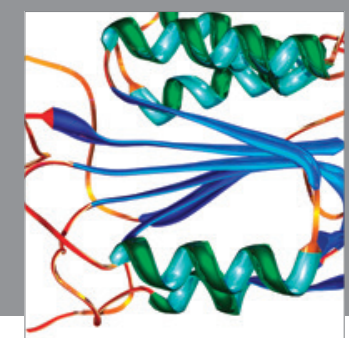

Disease Markers
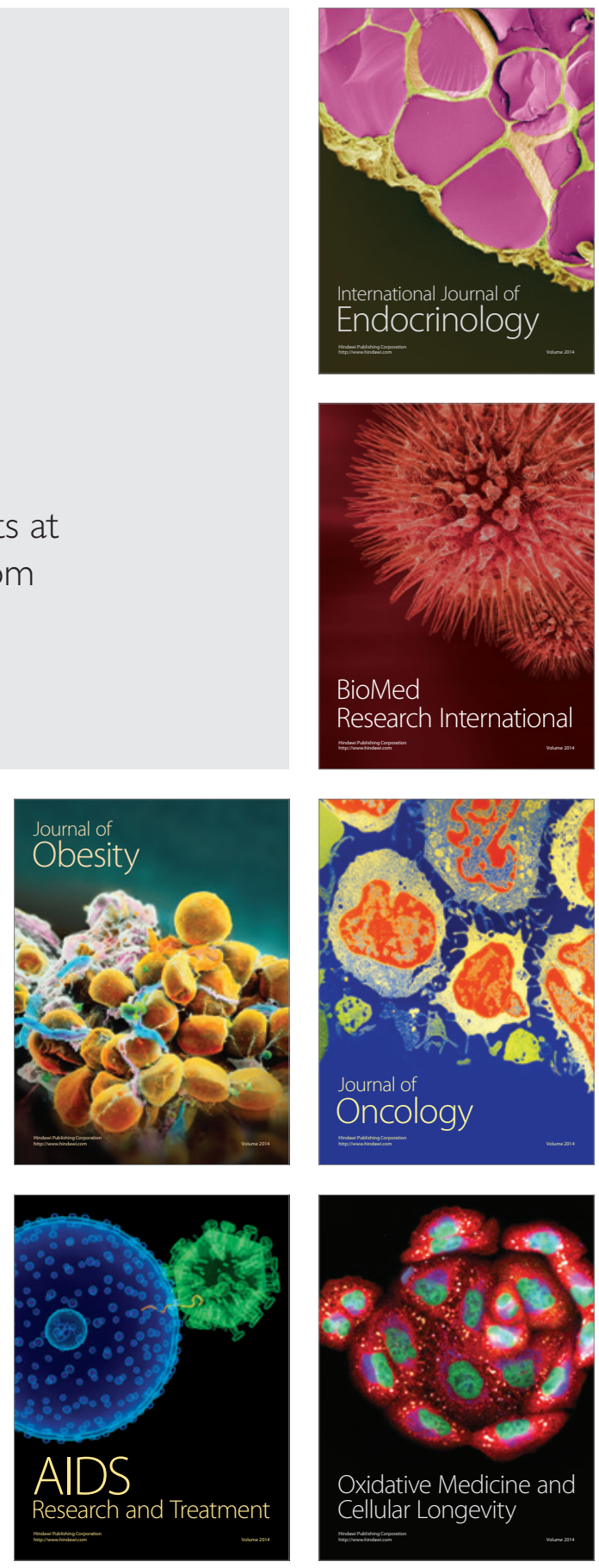